\title{
Produção do segundo ciclo do pinhão-manso irrigado com águas salinizadas em ambiente protegido ${ }^{1}$
}

\author{
Aparecida R. Nery ${ }^{2}$, Luis N. Rodrigues ${ }^{2}$, Pedro D. Fernandes ${ }^{3}$, \\ Lucia H. G. Chaves $^{4} \&$ Denise de J. L. Ferreira ${ }^{5}$
}

\begin{abstract}
RESUMO
Propôs-se, neste trabalho, estudar os efeitos da salinidade da água de irrigação sobre a produção do pinhãomanso (Jatropha curcas L.) após poda realizada aos 396 dias após a semeadura - DAS, em ambiente protegido. A pesquisa foi desenvolvida entre maio de 2008 e janeiro de 2009. A cultura foi conduzida em lisímetros de drenagem $(200 \mathrm{~L}$ ) contendo $230 \mathrm{~kg}$ de material de solo, Argissolo Acinzentado, devidamente adubado e corrigido. Testaram-se cinco níveis de condutividade elétrica da água de irrigação - CEa $(0,6 ; 1,2 ; 1,8 ; 2,4$ e 3,0 dS m$~^{-1}$, a $25^{\circ} \mathrm{C}$ ). Empregou-se o delineamento experimental em blocos inteiramente casualizados, com quatro repetições. As plantas foram podadas a $80 \mathrm{~cm}$, ao final do primeiro ciclo de produção. Aos 240 dias após a poda (DAPd), plantas irrigadas com água de 3,0 dS $\mathrm{m}^{-1}$ tiveram o número de cachos reduzido em $93 \%$, o peso médio das cascas, das sementes e dos frutos e número de frutos por planta reduzidos em $97 \%$. Os pesos médios do fruto e da semente foram reduzidos em 67 e $49 \%$, respectivamente. Plantas

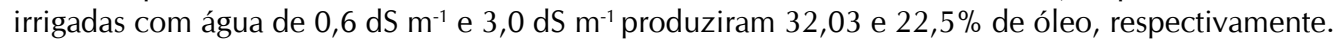

Palavras-chave: irrigação, condutividade elétrica, Jatropha curcas L., biodiesel

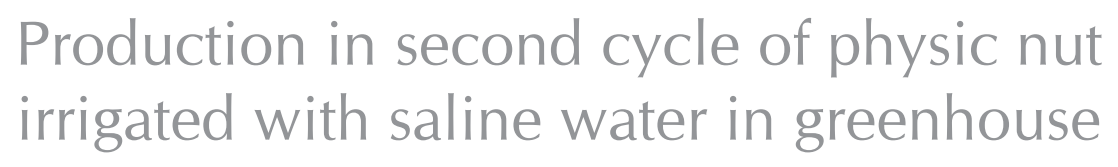

\begin{abstract}
The objective of this work was to evaluate the effects of the irrigation with saline water on production of physic nut (Jatropha curcas L.) after pruning (396 days after sowing). Between May 2008 and January 2009, the experiment was carried out in a greenhouse. The plants were grown in drainage lysimeters (200L) containing $230 \mathrm{~kg}$ of non-saline and non-sodic soil properly fertilized, classified as Gray Argisoil Eutrophic. Treatments consisted of five levels of electrical conductivity of the irrigation water - ECW $(0.6 ; 1.2 ; 1.8$; 2.4 and $3.0 \mathrm{dS} \mathrm{m}^{-1}$, at $25^{\circ} \mathrm{C}$ ). All the plants were pruned at $80 \mathrm{~cm}$ height. At 240 days after pruning the variables: number of bunches, weight of main of scab, seeds and fruits, weights of seed and fruit, number of fruits and oil content were evaluated. Plants irrigated with water of $3.0 \mathrm{dS} \mathrm{m} \mathrm{m}^{-1}$ were significantly affected with the following reductions: $93 \%$ in number of bunches, $97 \%$ in the variables weight of scab, of seeds and fruits, and number of fruits; $67 \%$ in fruit weight, and $49 \%$ in seed weight. Oil content of plants irrigated with water of $3.00 \mathrm{dS} \mathrm{m}^{-1}$ had reduction of $30.56 \%$.
\end{abstract}

Key words: irrigation, electrical conductivity, Jatropha curcas L., biodiesel

\footnotetext{
1 Parte da Tese de Doutorado do primeiro autor, apresentada ao Programa de Pós-Graduação em Engenharia Agrícola/UFCG

${ }^{2}$ IFPA CASTANHAL. Rod. Br 316, km 61, Saudade, IFPA - Campus Castanhal, Castanhal-PA. Fone: (91) 3412 - 1604. Email: cida.nery@ifpa.edu.br; cydanery@gmail.com

3 PRPGP/UEPB, UAEA/UFCG, Rua Antonio Joaquim Pequeno, 800, CEP 58429-105, Campina Grande, PB. Fone: (83) 8824-1448. E-mail: pdantas@pq.cnpq.br

${ }^{4}$ UAEA/UFCG. Av. Aprígio Veloso 882, CEP 58429-140. Campina Grande, PB. Fone: (83) 3310-1285. E-mail (s): Ihgarofalo@hotmail.com; djlf_deni@yahoo.com.br

${ }^{5}$ Doutoranda em Irrigação e Drenagem, Universidade Federal de Campina Grande - UFCG. Av. Aprígio Veloso 882, CEP 58429-140. Campina Grande, PB. Fone: (83) 2101-1318, E-mail: djlf_deni@yahoo.com.br
} 


\section{INTRODUÇÃO}

O Brasil e o mundo buscam alternativas de fontes renováveis de matérias-primas oleíferas de qualidade, para produção em bases competitivas. As espécies convencionais são culturas "com domínio tecnológico" e cadeias produtivas em organização crescente ou já consolidadas, incluindo-se nesta agenda a soja, o girassol, a mamona, o algodão e o dendê.

Dentre as espécies potenciais o pinhão-manso (Jatropha curcas L.) tem sido considerado uma das alternativas de interesse com acompanhamento, esforços, investimentos públicos, privados e está em processo de expansão de cultivo caracterizado não só pela iniciativa privada de plantio comercial mas também por ações técnico-científicas de domesticação, com experimentação científica e técnica continuada objetivando transformá-la de espécie selvagem em espécie cultivada (Durães \& Laviola, 2009).

O pinhão-manso é uma planta introduzida no Brasil há séculos e ocorre dispersa em grande parte do território nacional; pertence à família Euphorbiaceae, a mesma da mamona e da mandioca (Tominaga et al., 2007). É uma planta produtora de óleo com todas as qualidades necessárias para ser transformado em biodiesel.

Além de perene e de fácil cultivo a semente colhida se conserva facilmente podendo tornar-se boa fonte para produção opcional de combustível (Tominaga et al., 2007). Especialmente na década de 1980 e, mais recentemente, a partir de 2005, o pinhão-manso está sendo plantado em áreas comerciais e experimentais visando à geração de tecnologia para a produção de óleo (Durães \& Laviola, 2009).

Apesar da carência de informações técnicas básicas, a cultura vem sendo implantada e difundida em diferentes regiões do País e do mundo. Achten et al. (2009) alertam ainda que é preciso ter precaução quanto à exploração desenfreada pois isto poderá ser um obstáculo na obtenção do real potencial da cultura haja vista que a ciência precisa ser aplicada em tempo apropriado.

Um dos primeiros passos a ser delimitado ante a domesticação de uma espécie é a determinação do nível de aptidão agrícola para a região específica, o que exige um levantamento, organização e análise de dados climáticos peculiares às suas necessidades (Sediyama et al., 2001).

A realização do zoneamento agrícola de uma região visa obter maiores informações sobre a adaptabilidade das culturas selecionadas e, sobretudo, proporcionar maior retorno dos investimentos a médio e longo prazos para os produtores contribuindo, desta forma, para uma agricultura racional e sustentável (Nunes et al., 2007).

Nos sistemas de cultivo em solo o potencial mátrico tem grande contribuição na diminuição do potencial total da água (Cardoso \& Klar, 2009) dificultando a absorção de água pelas plantas; esta diminuição é ainda maior quando o potencial mátrico se soma ao potencial osmótico das águas salobras.

De acordo com Silva et al. (2008) cerca de 23.000 ha dos perímetros irrigados na região Nordeste estão afetados por sais. Nas regiões afetadas por sais a salinidade é considerada um dos principais estresses abióticos que afetam a produtividade e a qualidade das culturas (Gondim et al., 2010) induzindo redução no crescimento das plantas (Nery et al., 2009; Garcia et al., 2010; Oliveira et al., 2010) além do abandono de lotes de terra nos perímetros irrigados da região Nordeste brasileira. Devido às suas potencialidades, produtividade, rusticidade e, ainda, o fato de ser perene e persistente à seca, além de poder ser utilizada como cultura consorciada (Arruda et al., 2004) esta oleaginosa tem potencial para atender ao Programa Nacional de Produção de Biodiesel (PNPB).

Embora seja considerada, por diversos autores, uma planta tolerante e resistente às condições de seca adaptada à semiaridez, exigente em calor e luminosidade, a garantia de produção do pinhão-manso deverá ser maior com o fornecimento de água via irrigação.

Assim, a utilização da irrigação com águas de qualidade marginal (salinas) pode ser viável para atender às suas exigências hídricas e nutricionais, para fins de produção industrial.

\section{Material e Métodos}

A pesquisa foi desenvolvida entre os meses de maio de 2008 e janeiro de 2009, em instalações pertencentes ao Centro de Tecnologia e Recursos Naturais (CTRN) da Universidade Federal de Campina Grande (UFCG), Campina Grande, PB, com as seguintes coordenadas geográficas: latitude $07^{\circ} 13^{\prime} \mathrm{S}$, longitude $35^{\circ} 53^{\prime} \mathrm{W}$ e altitude média $550 \mathrm{~m}$.

A pesquisa foi realizada com o pinhão-manso (Jatropha curcas L.), seleção FT-02, cedida pelo Instituto Fazenda Tamanduá, localizado no município de Santa Terezinha, PB. $\mathrm{O}$ experimento foi conduzido e avaliado no segundo ciclo de produção da cultura submetida, inicialmente, à poda drástica a $80 \mathrm{~cm}$, aos 396 dias após transplantio.

O material de solo (Argissolo Acinzentado Eutrófico) procedente do Distrito de São José da Mata (Campina Grande) foi coletado na profundidade de $0-30 \mathrm{~cm}$ (horizonte A).

Utilizaram-se 40 lisímetros de drenagem com capacidade de $200 \mathrm{~L}(\mathrm{D}=0,58 \mathrm{~m}$ e $\mathrm{H}=0,75 \mathrm{~m}$ ) cada um contendo $230 \mathrm{~kg}$ de material de solo; o sistema de drenagem foi composto de tela de nylon, 5,0 L de brita, 5,0 L de areia, mangueira e dois recipientes coletores de $2 \mathrm{~L}$.

Cinco níveis de condutividade elétrica da água de irrigação - $\operatorname{CEa}\left(\mathrm{N}_{1}=0,60 ; \mathrm{N}_{2}=1,20 ; \mathrm{N}_{3}=1,80 ; \mathrm{N}_{4}=2,40\right.$ e $\mathrm{N}_{5}=$ $3,00 \mathrm{dS} \mathrm{m}^{-1}$, a $25^{\circ} \mathrm{C}$ ) foram testados e delineados em blocos casualizados, com quatro repetições, sendo a parcela constituída de 2 plantas (1 planta por lisímetro) perfazendo o total de 40 lisímetros ( 5 níveis $\mathrm{x} 4$ blocos $\mathrm{x} 2$ vasos por parcela); as p arcelas experimentais ficaram espaçadas $1,70 \mathrm{~m} \times 1,40 \mathrm{~m}$ dentro do bloco e 1,60 m entre blocos.

Para o preparo das soluções salinas foram utilizados os sais cloreto de sódio $(\mathrm{NaCl})$, cloreto de cálcio $\left(\mathrm{CaCl}_{2} \cdot 2 \mathrm{H}_{2} \mathrm{O}\right)$ e cloreto de magnésio $\left(\mathrm{MgCl}_{2} .6 \mathrm{H}_{2} \mathrm{O}\right)$, na proporção equivalente $7: 2: 1$, entre os cátions $\mathrm{Na}^{+}: \mathrm{Ca}^{2+}: \mathrm{Mg}^{++}$, relação esta baseada em resultados de estudos realizados por Medeiros (1992) em águas de pequenos mananciais do Nordeste brasileiro; as águas preparadas foram acondicionadas em recipientes fechados. $\mathrm{Na}$ composição das águas salinas utilizou-se da água de abastecimento público.

O início da aplicação dos tratamentos ocorreu aos 3 dias após poda - DAPd, com turno de rega de 3 dias; as plantas foram 
irrigadas sob diferentes frações de lixiviação, 4, 8, 12, 16 e $20 \%$ para os tratamentos $\mathrm{N}_{1}, \mathrm{~N}_{2}, \mathrm{~N}_{3}, \mathrm{~N}_{4}$ e $\mathrm{N}_{5}$, respectivamente.

As irrigações foram manejadas e controladas mediante $o$ uso de planilha eletrônica contendo o balanço hídrico durante o período experimental; os volumes de irrigação variaram em função do balanço hídrico e das frações de lixiviação.

Para o segundo ano (após poda) foram realizadas mensalmente não só adubações de cobertura com N-P-K e adubações foliares com micronutrientes, em especial para suprir a deficiência de zinco e cobre, mas também pulverizações para o controle de várias pragas, dentre elas pulgões, cigarrinha, mosca branca e, sobretudo, para o controle do ácaro branco, Polyphagotarsonemus latus banks.

Para os tratamentos fitossanitários foram adotadas todas as medidas culturais indicadas para o controle, bem como a rotação dos agroquímicos com extrato vegetal (óleo de pinhão-manso) objetivando evitar o surgimento de resistência.

No final do segundo ciclo (240 DAPd) foram avaliados as variáveis número de cachos por planta, peso médio das cascas, sementes e frutos, peso médio do fruto e da semente, número de frutos e teor de óleo.

O número de cachos foi determinado mediante identificação de cada cacho na planta com a amarração de um fitilho; aos 240 dias foi realizada a contagem do número de fitilhos de cada planta correspondendo ao número de cachos por planta.

Os frutos colhidos a cada três dias foram postos para secagem ao ar durante três a quatro dias; após este prazo os frutos foram pesados em balança de precisão $(0,01 \mathrm{~g})$ e em seguida à pesagem os frutos foram separados em cacas e sementes, que foram também pesadas; ao final obtiveramse, com a somatória das sucessivas pesagens registradas em planilhas, os pesos totais correspondentes.

O teor de óleo nas sementes (expresso em \%) foi determinado no Laboratório da Embrapa CNPA em Campina Grande, mediante o uso da técnica Ressonância Magnética Nuclear (RMN) em espectrofotômetro, marca Oxford 4000. De cada amostra foram feitas três repetições de leituras, obtendo-se a média como o valor da parcela.

Os dados foram tabulados e submetidos às análises de variância, de média e de regressão polinomial. De acordo com Santos et al. (1998) os quatro graus de liberdade dos tratamentos 'N' (níveis salinos) foram decompostos em componentes de regressão polinomial (linear, quadrática, cúbica e de quarto grau).

\section{Resultados e Discussão}

A produção de pinhão-manso varia diretamente com o número de cachos produzidos por planta, daí ser uma das variáveis mais importantes. Sabe-se que a produção depende de vários fatores e que o potencial produtivo só é manifestado se todos os fatores estiverem otimizados, dentre os quais se citam clima da região, qualidade da semente, sistema de produção, fitossanidade, fertilidade do solo, dentre outros.

Perante a Tabela 1 constata-se que os níveis salinos afetaram significativamente o número de cachos a nível de 0,01 de probabilidade cujos dados se ajustaram melhor ao modelo quadrático (Figura 1A). Mesmo sob comportamento quadrático estimam-se decréscimos entre $\mathrm{N}_{1}\left(0,60 \mathrm{dS} \mathrm{m}^{-1}\right)$ e os sucessivos níveis crescentes de $37,57,65,57,84,01,92,88 \%$.

$\mathrm{O}$ aumento da CEa na água de irrigação contribuiu para a baixa produção das plantas; as plantas irrigadas com água de $3,00 \mathrm{dS} \mathrm{m}^{-1}$ até os 240 dias após a poda produziram 1 ou no máximo 2 cachos.

Nery et al. (2009) concluíram, no primeiro ciclo de produção, que o número de cachos e o número de frutos por planta não foram afetados até o nível salino de $1,80 \mathrm{dS} \mathrm{m}^{-1}$, valor este considerado como a salinidade limiar da água de irrigação para esses componentes de produção.

Silva et al. (2011) concluíram que o estresse hídrico afeta todas as variáveis de produção das plantas de pinhão-manso. Entre os tratamentos com 25 e $125 \%$ de reposição da ETc, os autores registraram aumento de $648,80 \%$ no número de cachos durante o primeiro ano de cultivo do pinhão-manso.

Mediante análise da Tabela 1, houve efeito quadrático da CEa sobre as fitomassas de cascas, sementes e frutos, a nível de 0,01 de probabilidade.

O desempenho das plantas submetidas aos diferentes níveis salinos está representado na Figura 1B, C, D. Os resultados se ajustaram a regressões quadráticas $(\mathrm{P}<0,01)$ com elevados coeficientes de determinação $\left(\mathrm{R}^{2}\right)$ que explicam o elevado grau de associação entre a CEa e as respostas das plantas.

Embora com efeito quadrático, conferem-se decréscimos com o incremento da salinidade de água sobre o peso médio das cascas, sementes e frutos. Os decréscimos entre $\mathrm{N}_{1}(0,60$ $\left.\mathrm{dS} \mathrm{m} \mathrm{m}^{-1}\right)$ e $\mathrm{N}_{5}\left(3,00 \mathrm{dS} \mathrm{m}^{-1}\right)$ para essas variáveis foram da ordem de $97,00 \%$, cerca de $40,42 \%$ por aumento unitário de CEa.

Tabela 1. Resumo das análises de variância e médias para as variáveis dos componentes de produção do pinhãomanso (número de cachos, peso médio de cascas, peso médio de sementes, peso médio de frutos, peso médio de 1 fruto, peso médio da semente, número médio de frutos e teor de óleo). Campina Grande, PB, 2009

\begin{tabular}{|c|c|c|c|c|c|c|c|c|c|}
\hline \multirow{3}{*}{$\begin{array}{l}\text { Fonte de } \\
\text { variação }\end{array}$} & \multirow{3}{*}{ GL } & \multicolumn{8}{|c|}{ Quadrados médios } \\
\hline & & \multirow{2}{*}{$\begin{array}{c}\mathrm{N}^{0} \mathrm{de} \\
\text { cachos }\end{array}$} & \multicolumn{5}{|c|}{ Peso médio } & \multirow{2}{*}{$\begin{array}{l}\text { No médio } \\
\text { de frutos }\end{array}$} & \multirow{2}{*}{ Teor de óleo } \\
\hline & & & de cascas & de sementes & de frutos & do fruto & da semente & & \\
\hline N. sal. (N) & 4 & $1211,21^{* *}$ & $5322,73^{* *}$ & $23423,20^{\star \star}$ & $50386,30^{* \star}$ & $1,98^{* *}$ & $1,34^{* *}$ & $8280,80^{* *}$ & $1022,55^{\star \star}$ \\
\hline R. linear & 1 & $571,13^{\star \star}$ & $1084,40^{\star}$ & $5220,65^{\star}$ & $8901,32^{\star}$ & $0,86^{\star \star}$ & 4,24 ** & 31691,60 ** & $3992,54 * \star$ \\
\hline R. quadrática & 1 & $4250,32^{\star \star}$ & $19599,51^{* *}$ & $86991,97^{\star \star}$ & $189326,92^{\star \star}$ & $7,03^{\star \star}$ & $0,81^{\star *}$ & $297,78^{\text {ns }}$ & $105,92^{\text {ns }}$ \\
\hline R. cúbica & 1 & $10,22^{\text {ns }}$ & $282,23^{\text {ns }}$ & $217,16^{\text {ns }}$ & $927,95^{\text {ns }}$ & $0,00^{\text {ns }}$ & $0,17^{\text {ns }}$ & $276,90^{\text {ns }}$ & $4,70^{\text {ns }}$ \\
\hline R. $4^{0}$ grau & 1 & $13,18^{\text {ns }}$ & $324,80^{\text {ns }}$ & $1263,02^{\text {ns }}$ & $2389,03^{\text {ns }}$ & $0,00^{\text {ns }}$ & $0,11^{\text {ns }}$ & $856,91^{\text {ns }}$ & $13,25^{\text {ns }}$ \\
\hline Blocos & 3 & $9,08^{\text {ns }}$ & $274,49^{\text {ns }}$ & $1335,90^{\text {ns }}$ & $2935,71^{\text {ns }}$ & $0,02^{\mathrm{ns}}$ & $0,06^{\mathrm{ns}}$ & $577.40^{\text {ns }}$ & $26,29^{\text {ns }}$ \\
\hline Resíduo & 27 & 3,32 & 148,71 & 732,60 & 1484,69 & 0,04 & 0,05 & 236,07 & 27,74 \\
\hline CV (\%) & & 32,66 & 33,93 & 40,85 & 37,36 & 14,74 & 17,52 & 25,48 & 19,69 \\
\hline Média & & 5,58 & $35,94 \mathrm{~g}$ & $66,25 \mathrm{~g}$ & $102,20 \mathrm{~g}$ & $1,30 \mathrm{~g}$ & $1,29 \mathrm{~g}$ & 60,30 & $26,75 \%$ \\
\hline
\end{tabular}

$\left({ }^{\star *}\right)$ Significativo a 0,01 de probabilidade; $\left(^{*}\right)$ Significativo a 0,05 de probabilidade; $\left({ }^{(s)}\right.$ não significativo a 0,05 de probabilidade pelo teste $F$ 
A.

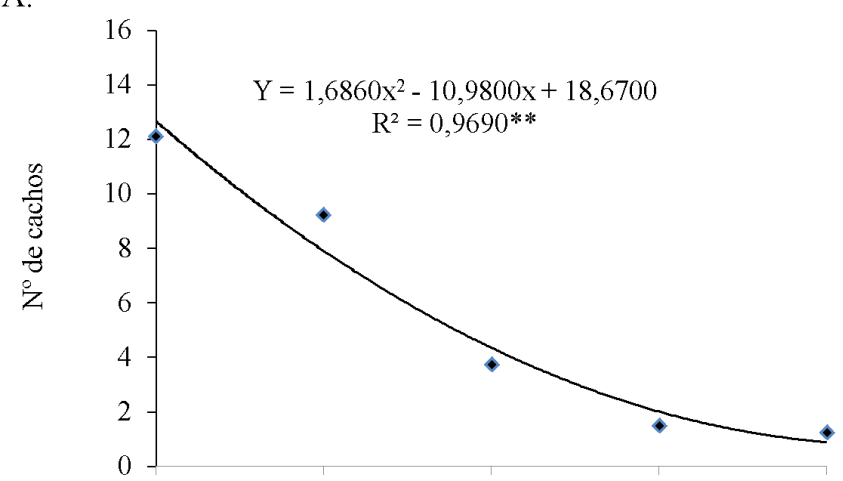

B.

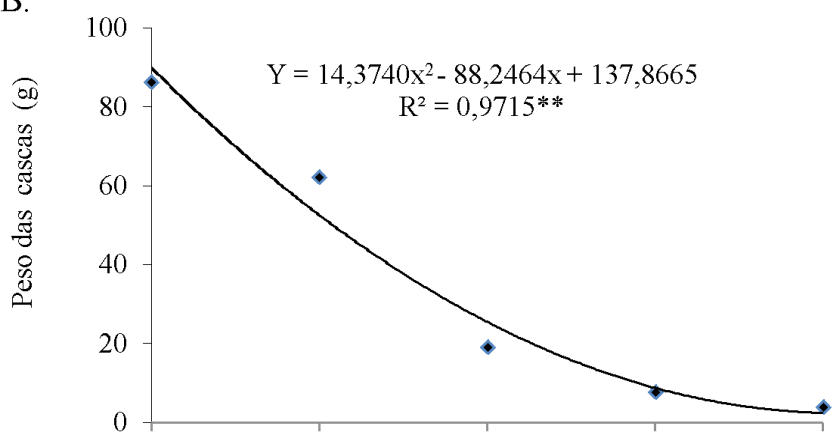

C.

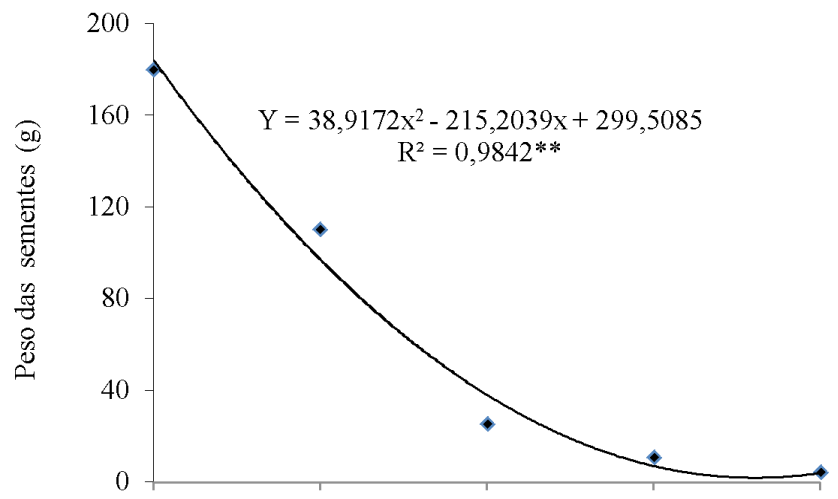

D.

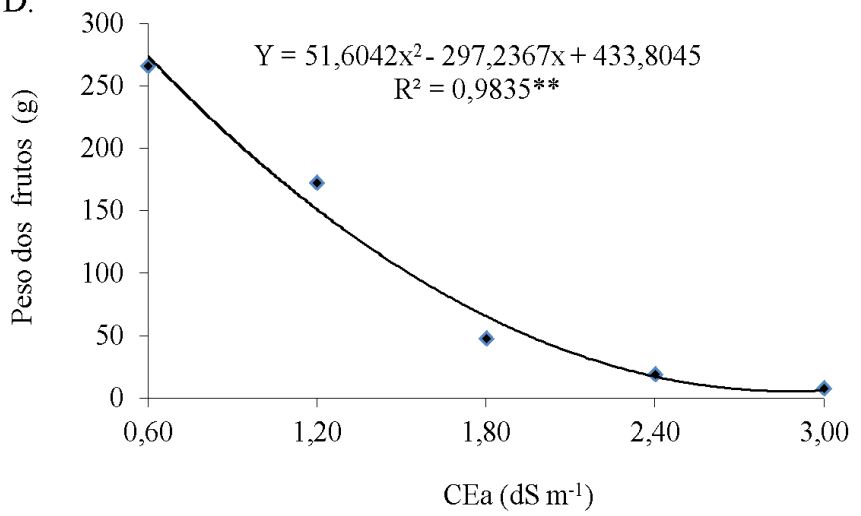

Figura 1. Componentes de produção do pinhão-manso (número de cachos $(\mathrm{A})$, peso das cascas $(\mathrm{B})$, peso das sementes (C) e peso dos frutos (D)) aos 240 dias após a poda, em função da condutividade elétrica da água de irrigação (CEa)

Nery (2008) verificou, durante o primeiro ciclo, que as biomassas de frutos, cascas e sementes do primeiro cacho, não foram afetadas pela condutividade elétrica da água de irrigação notando-se, inclusive, incremento dessas variáveis até o nível de $1,80 \mathrm{dS} \mathrm{m}^{-1}$.

Analisando a média geral (Tabela 1) da fitomassa de cascas $(35,94 \mathrm{~g})$ e da fitomassa de sementes $(66,25 \mathrm{~g})$ deduz-se que as cascas e sementes representam 35 e $65 \%$ da fitomassa total dos frutos, respectivamente.

Durante o primeiro ciclo Nery (2008) estimou a biomassa de frutos do primeiro cacho resultando em $35,50 \mathrm{~g}$ em média, sendo aproximadamente $29,60 \%$ de casca $(10,50 \mathrm{~g})$ e $70,40 \%$ de semente $(25 \mathrm{~g})$ caso em que as sementes tiveram maior contribuição no peso dos frutos.

Carneiro et al. (2009) concluíram que a aplicação de águas a partir de $1,0 \mathrm{dS} \mathrm{m}^{-1}$ de salinidade inibe as produções de fitomassas e os efeitos são mais intensos sobre o sistema radicular que sobre a parte aérea resultando em diminuição na relação raiz/parte aérea da espécie Jatropha curcas.

Soares et al. (2009) verificaram grande variabilidade na produção de pinhão-manso obtida oscilando de 73,4 a 688,2 g por planta, durante toda a safra produtiva, que ocorreu de novembro de 2008 a julho de 2009.

Apresentam-se, na Tabela 1, os resumos estatísticos do peso médio do fruto e peso médio da semente que também foram significativamente afetados pelos tratamentos $(\mathrm{P}<0,01)$. Pelas mesmas razões expostas para as variáveis anteriores, os dados do peso unitário do fruto se ajustaram melhor ao modelo matemático quadrático (Figura 2A) enquanto os dados do peso médio da semente se ajustaram ao modelo linear (Figura 2B).

Com base nas médias observadas as plantas irrigadas com água de $\mathrm{CE}$ de $3,00 \mathrm{dS} \mathrm{m}^{-1}(0,75 \mathrm{~g})$ sofreram redução de $67 \%$ sobre o peso médio do fruto quando comparadas com aquelas irrigadas com água de CEa de $0,60 \mathrm{dS} \mathrm{m}^{-1}(2,26 \mathrm{~g})$ correspondente à redução de $27,92 \%$ para cada unidade de condutividade elétrica da água de irrigação.

Utilizando da equação linear apresentada na Figura 2B, estima-se que o peso médio da semente teve redução de $49,44 \%$ nas plantas irrigadas com água de $3,00 \mathrm{dS} \mathrm{m}^{-1}$ comparadas com aquelas irrigadas com água de $0,60 \mathrm{dS} \mathrm{m}^{-1}$; este efeito pode ser explicado em função do coeficiente angular, com redução de $0,352 \mathrm{~g}$ no peso da semente para cada $\mathrm{dS} \mathrm{m}^{-1}$.

Veras et al. (2011) concluíram que o pinhão-manso pode ser classificado como tolerante à salinidade, com produção de sementes favorecida até $4,0 \mathrm{dS} \mathrm{m}^{-1}$ e que a maior produção de sementes é obtida com água salina de $2,28 \mathrm{dS} \mathrm{m}^{-1}$.

Ainda pela Tabela 1 o número de frutos também foi significativamente afetado pela salinidade da água de irrigação a nível de 0,01 de probabilidade. Para esta variável os dados também foram ajustados ao modelo linear explicando melhor as respostas das plantas de pinhão-manso (Figura 2C).

Os decréscimos lineares entre $\mathrm{N}_{1}\left(0,60 \mathrm{dS} \mathrm{m}^{-1}\right)$ e os demais níveis foram $24,25,48,50,72,75,97 \%$, cerca de $40,42 \%$ de redução por incremento unitário na $\mathrm{CEa}$ ou, pelo coeficiente angular, 47,33 frutos por $\mathrm{dS} \mathrm{m}^{-1}$.

Durante o primeiro ciclo Nery (2008) elegeu, com base nos resultados obtidos, elegeu 1,80 $\mathrm{dS} \mathrm{m}^{-1}$, como salinidade limiar da água de irrigação uma vez que CE maiores contribuíram decisivamente para a queda de produção. 
A.

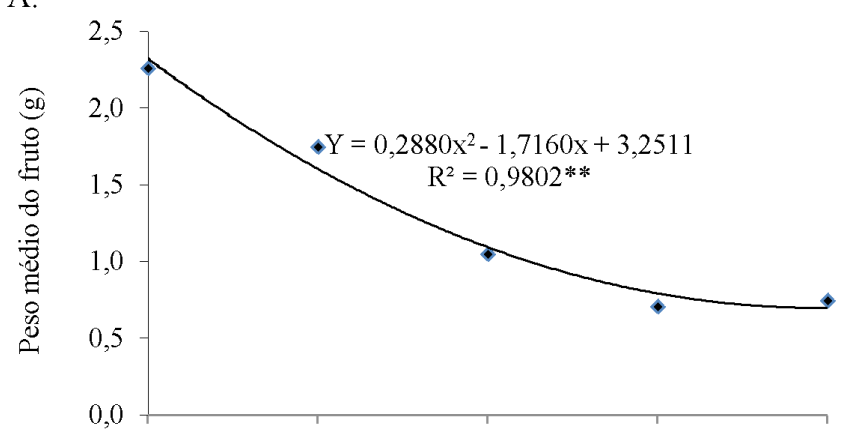

B.

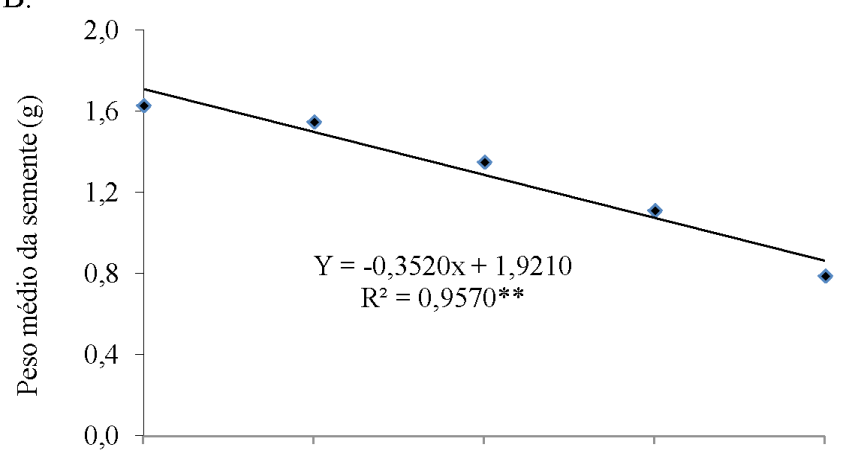

C.

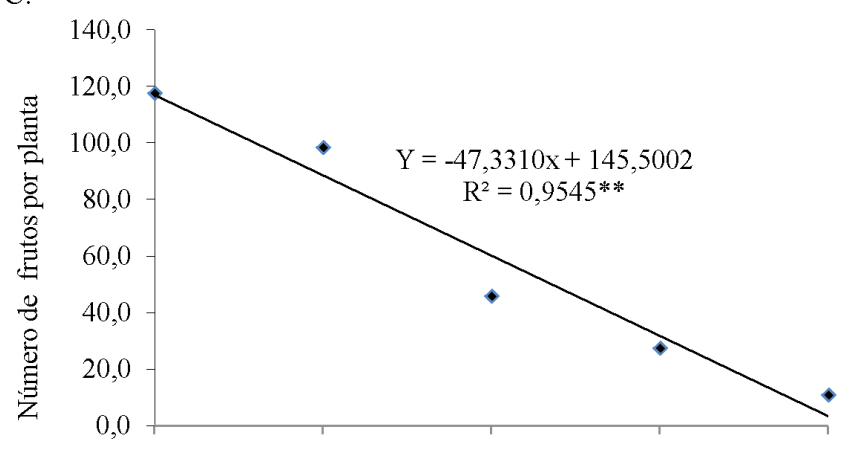

D.

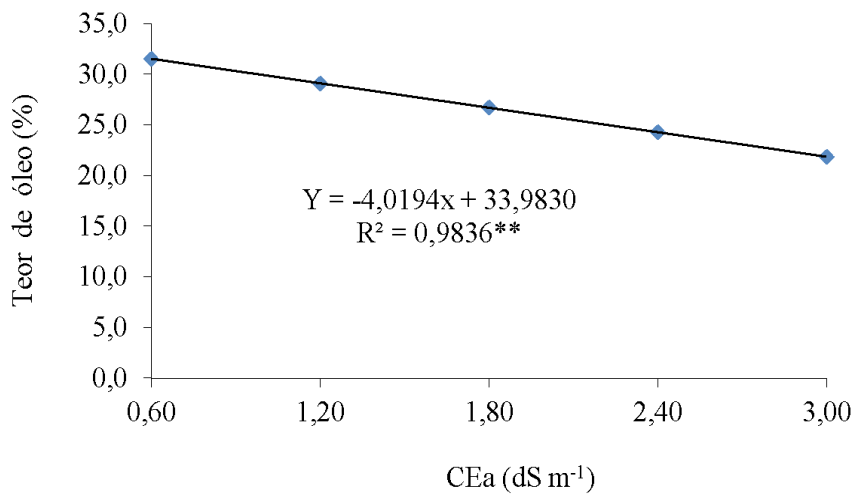

Figura 2. Componentes de produção do pinhão-manso (peso médio do fruto $(A)$, peso médio da semente (B), número médio de frutos por planta $(C)$ e teor de óleo (D)) aos 240 dias após a poda, em função da condutividade elétrica da água de irrigação (CEa)

Já nesta pesquisa (segundo ciclo com plantas podadas) pelos resultados obtidos para as variáveis de fitomassa (variáveis antecedentes) bem como para o número de frutos, nota-se elevada sensibilidade do pinhão-manso à salinidade da água de irrigação que contribuiu categoricamente para a queda de produção.
Observou-se efeito linear significativo da salinidade da água de irrigação $(\mathrm{P}<0,01)$ sobre o teor de óleo das sementes de pinhão-manso (Tabela 1).

Empregando o modelo matemático contido na Figura 2D, estima-se que as plantas irrigadas com água de $3 \mathrm{dS} \mathrm{m}^{-1}$ tiveram redução de $30,56 \%$ no teor de óleo das sementes quando comparadas com aquelas irrigadas com água de $0,60 \mathrm{dS} \mathrm{m}^{-1}$. Igualmente, deduz-se que para o incremento unitário da $\mathrm{CEa}$ o teor de óleo teve redução de $12,73 \%$ em termos relativos ou $4,02 \mathrm{em}$ termos absolutos.

Nota-se elevado grau de associação $\left(\mathrm{R}^{2}=0,98\right)$ entre os níveis salinos e o teor de óleo. Ficou evidenciada a sensibilidade da planta do pinhão-manso à salinidade da água de irrigação. Percebe-se também que o teor de óleo foi inferior aos registrados por outros autores, mesmo sob nível mais baixo de $\mathrm{CEa}\left(0,60 \mathrm{dS} \mathrm{m}^{-1}\right)$.

A produtividade de óleo por hectare é função direta do teor de óleo (\%) e da produtividade da cultura $\left(\mathrm{kg} \mathrm{ha}^{-1}\right)$. Como a produção de sementes foi severamente afetada pela salinidade de água e ao lado das progressivas reduções no teor de óleo, infere-se que a planta de pinhão, nas condições desta pesquisa, pode ser considerada sensível.

É conveniente salientar que as plantas irrigadas com água de $0,60 \mathrm{dS} \mathrm{m}^{-1}$ produziram mais bagas e maior quantidade de óleo, o que implica em afirmar que tais plantas produzem melhor em quantidade e qualidade.

Souza et al. (2010) constataram que a irrigação com esgoto doméstico tratado contribuiu para o aumento da produtividade da mamona porém o teor de óleo foi maior nos tratamentos com a adubação convencional recomendada.

Soares et al. (2009) verificaram variação em relação ao teor de óleo nas sementes de pinhão-manso sendo o menor valor obtido de $24,39 \%$ e o máximo de $37,86 \%$ e que ocorreu correlação negativa indicando que plantas que produzem mais sementes normalmente não produzem sementes com os maiores teores de óleo.

Os resultados evidenciam o efeito deletério da salinidade sobre as plantas, resultando em redução no desenvolvimento das plantas e nos teores de macronutrientes catiônicos (Baghalian et al., 2008). De acordo com alguns autores o estresse nutricional em plantas sob estresse salino pode estar associado ao acúmulo excessivo de determinados íons e à redução na aquisição de outros, em virtude das alterações na disponibilidade de nutrientes, da competição no processo de absorção e à inibição do transporte na planta (Blanco et al., 2008; Neves et al., 2009; Gurgel et al., 2010).

\section{Conclusões}

1. O número de cachos e o número de frutos e a biomassa de cascas, sementes e frutos, são reduzidos em mais de $90 \%$ nas plantas irrigadas com água de $3,00 \mathrm{dS} \mathrm{m}^{-1}$.

2. O peso médio de semente e de fruto é reduzido em 20,60 e $27,92 \%$, respectivamente, por aumento unitário da condutividade elétrica na água de irrigação.

3. As plantas do pinhão-manso produzem, em média, $32,03 \%$ de óleo quando irrigadas com água salina de $0,60 \mathrm{dS}$ 
$\mathrm{m}^{-1}$ e $22,92 \%$ de óleo com água de 3,0 dS m $\mathrm{m}^{-1}$, correspondendo a uma redução de $30,55 \%$ entre os níveis de salinidade.

\section{Literatura Citada}

Achten, W. M. J.; Verchot, L.; Franken, Y. J.; Mathijs, E.; Singh, V. P.; Aerts, R.; Muys, B. Jatropha bio-diesel production and use. Biomass and Bioenergy, v.32, p.10631084, 2009.

Arruda, F. P. de; Beltrão, N. E. de M.; Andrade, A. P. de; Pereira, W. E.; Severino, L. S. Cultivo do pinhão manso (Jatropha curcas L.) como alternativa para o semiárido nordestino. Revista Brasileira de Oleaginosas e Fibrosas, v.8, p.789799, 2004.

Baghalian, K.; Haghiry, A.; Naghavi, M. R.; Mohammadi, A. Effect of saline irrigation water on agronomical and phytochemical characters of chamomile (Matricaria recutita L.). Scientia Horticulturae, v.116, p.437-441, 2008.

Blanco, F. F.; Folegatti, M. V.; Henriques Neto, D. Doses de $\mathrm{N}$ e K no tomateiro sob estresse salino: I. Concentração de nutrientes no solo e na planta. Revista Brasileira de Engenharia Agrícola e Ambiental, v.12, p.26-33, 2008.

Cardoso, G. G. G.; Klar, A. E. Potenciais de água no solo na produção de alface. Irriga, v.14, p.170-179, 2009.

Carneiro, P. T.; Silva, J. V.; Santos, M. A. L.; Santos Neto, A. L.; Santos, C. S. Produção de fitomassa do pinhão manso irrigado com águas salinas. In: Congresso Brasileiro de Pesquisas de Pinhão Manso, 1, 2009, Brasília. Anais... Brasília: Embrapa e ABPPM, 2009. CD-Rom

Durães, F. O. M.; Laviola, B. Pinhão Manso: Oleaginosa potencial para o biodiesel. Jornal Agroenergia, edição especial, Embrapa Agroenergia, 2009. 8p. http://www. cnpae.embrapa.br. 20 Mai. 2011.

Garcia, G. O.; Nazário, A. A.; Moraes, W. B.; Gonçalves, I. Z.; Madalão, J. C. Respostas de genótipos de feijoeiro à salinidade. Engenharia na Agricultura, v.18, p.330-338, 2010.

Gondim, F. A.; Gomes Filho, E.; Lacerda, C. F.; Prisco, J. T.; Azevedo Neto, A. D.; Marques, E. C. Pretreatment with $\mathrm{H}_{2} \mathrm{O}_{2}$ in maize seeds: Effects on germination and seedling acclimation to salt stress. Brazilian Journal of Plant Physiology, v.22, p.103-112, 2010.

Gurgel, M. T.; Uyeda, C. A.; Gheyi, H. R.; Oliveira, F. H. T.; Fernandes, P. D.; Silva, F. V. Crescimento de meloeiro sob estresse salino e doses de potássio. Revista Brasileira de Engenharia Agrícola e Ambiental, v.14, p.3-10, 2010.

Medeiros, J. F. de. Qualidade de água de irrigação e evolução da salinidade nas propriedades assistidas pelo GAT nos Estados de RN, PB e CE. Campina Grande: UFPB, 1992. 173p. Dissertação Mestrado

Nery, A. R. Crescimento e desenvolvimento do pinhão-manso irrigado com águas salinas sob ambiente protegido. Campina Grande: UFCG, 2008. 116p. Dissertação Mestrado
Nery, A. R.; Rodrigues, L. N.; Silva, M. B. R.; Fernandes, P. D.; Chaves, L. H. G.; Dantas Neto, J.; Gheyi, H. R. Crescimento do pinhão-manso irrigado com águas salinas em ambiente protegido. Revista Brasileira de Engenharia Agrícola e Ambiental, v.13, p.551-558, 2009.

Neves, A. L. R.; Lacerda, C. F. de; Guimarães, F. V. A.; Gomes Filho, E.; Feitosa, D. R. C. Trocas gasosas e teores de minerais no feijão-de-corda irrigado com água salina em diferentes estádios. Revista Brasileira de Engenharia Agrícola e Ambiental, v.13, p.873-881, 2009.

Nunes, E. L.; Amorim, R. C F.; Sousa, W. G.; Ribeiro, A.; Senna, M. C. A.; Leal, B. G. Zoneamento agroclimático da cultura do café para a bacia do Rio Doce. Revista Brasileira de Meteorologia, v.22, p.297-302, 2007.

Oliveira, I. R. S.; Oliveira, F. N.; Medeiros, M. A.; Torres, S. B.; Teixeira, F. J. V. Crescimento inicial do pinhão-manso (Jatropha curcas L.) em função da salinidade de água de irrigação. Caatinga, v.23, p.40-45, 2010.

Santos, J. W. dos; Moreira, J. A. N.; Beltrão, N. E. de M. Avaliação do emprego dos testes de comparação de médias na revista Pesquisa Agropecuária Brasileira (PAB) de 1980 a 1994. Pesquisa Agropecuária Brasileira, v.33, p.225-230, 1998.

Sediyama, G. C. Melo Júnior, J. C. F.; Santos, A. R.; Ribeiro, A. Costa, M. H.; Hamakawa, P. J.; Costa, J. M. N.; Costa, L. C. Zoneamento agroclimático do cafeeiro (Coffea arabica L.) para o estado de Minas Gerais. Revista Brasileira de Agrometeorologia, v.9, p.501-509, 2001.

Silva, E. C.; Nogueira, R. J. M. C.; Araújo, F. P.; Melo, N. F.; Azevedo Neto, A. D. Physiological responses to salt stress in young umbu plants. Environmental and Experimental Botany, v.63, p.147-157, 2008.

Silva, M. B. R. da; Fernandes, P. D.; Dantas Neto, J.; Nery, A. R.; Rodrigues, L. N.; Viégas, R. A. Crescimento e produção do pinhão-manso irrigado com água residuária sob condições de estresse hídrico. Revista Brasileira de Engenharia Agrícola e Ambiental, v.15, p.621-629, 2011.

Soares, B. O.; Juhàsz, A. C. P.; Pimenta, S.; Rabello, H. O. Correlação entre produtividade e teor de óleo em Jatropha curcas L. In: Congresso Brasileiro de Pesquisas de Pinhão Manso. 1, 2009, Brasília. Anais... Brasília: Embrapa e ABPPM, 2009. CD-Rom

Souza, N. C.; Mota, S. B.; Bezerra, F. M. L.; Aquino, B. F.; Santos, A. B. Produtividade da mamona irrigada com esgoto doméstico tratado. Revista Brasileira de Engenharia Agrícola e Ambiental, v.14, p.478-482, 2010.

Tominaga, N.; Kakida, J.; Yasuda, E.K.; Sousa, L. A. S.; Resende, P. L.; Silva, N. D. Cultivo do pinhão-manso para produção de biodiesel. Viçosa: Centro de Produções Técnicas, 2007. 220p.

Veras, R. P.; Laime, E. M. O.; Fernandes, P. D.; Soares, F. A. L.; Freire, E. A. Altura de planta, diâmetro caulinar e produção do pinhão-manso sob diferentes níveis de salinidade. Revista Brasileira de Engenharia Agrícola e Ambiental, v.15, p.582$587,2011$. 